\title{
O SISTEMA PRISIONAL BRASILEIRO E A DIGNIDADE DAS PESSOAS TRANSEXUAIS, TRAVESTIS E TRANSGÊNEROS: UM ESTUDO DE CASO DO HABEAS CORPUS N ${ }^{\circ}$ 497.226/RS
}

\author{
Emerson da Silva Mendes ${ }^{1}$ \\ Cristina Groberio Pazó ${ }^{2}$
}

Resumo: Importa-nos para a presente pesquisa analisar à luz do Princípio Constitucional da Dignidade da Pessoa Humana qual relação: os corpos de pessoas Transexuais, Travestis e Transgêneros estabelecem com o Sistema de Justiça, em específico com o Sistema Prisional Brasileiro? Diante do presente quadro utilizamos como metodologia de pesquisa estudos bibliográficos, recorrendo ao método hipotético dedutivo apoiando-se no estudo do caso D.S.S do Rio Grande do Sul (RS) por meio do Habeas Corpus (HC) nº 497.226 - Rs (2019/0065773-1) proferido pelo Ministro Rogerio Schietti Cruz do Supremo Tribunal de Justiça (STJ) e demais peças processuais do caso que esteja com acesso público, alinhado à análise de documentos oficiais que norteiam a política da República Federativa do Brasil no âmbito do Sistema Prisional. Diante do exposto, observou-se que a proteção oferecida pelo Estado tem-se mostrado insuficiente diante do complexo processo de violação de Direitos Humanos, além de uma potencial colapso no sistema de segurança pública.

Palavras-chaves: LGBTI+. Habeas Corpus. Sistema Prisional. Privação de Liberdade. Direitos Humanos.

\begin{abstract}
It is important for us, to the present research, to analyze under the light of the Constitutional Principle of Dignity of the Human Person, what relation do the bodies of Transsexual, Transvestites and Transgender people
\end{abstract}

\footnotetext{
${ }^{1}$ Discente do Programa de Pós-Graduando Lato Sensu em Gênero e Sexualidade na Educação pela Universidade Federal da Bahia (UFBA); Graduação em andamento no Curso de Bacharelado em Direito pela Universidade Federal do Sul da Bahia; Bacharel Interdisciplinar em Humanidades pela Universidade Federal do Sul da Bahia (2017).

${ }^{2}$ Professora Adjunta da Universidade Federal do Sul da Bahia. Possui Doutorado em Direito pela Universidade Gama Filho (2006); Mestrado em Direito pela Universidade Federal de Santa Catarina (2001) e Graduação em Direito pela Universidade Federal do Espírito Santo (1997).
} 
establish with the Justice System, specifically within Brazilian Prison System? At the present framework, we used as a research methodology bibliographical studies, using the hypothetical deductive method, based on the study of the case DSS of Rio Grande do Sul (RS) through Habeas Corpus (HC) no 497.226 - Rs (2019 / 0065773 1) uttered by Minister Rogerio Schietti Cruz of the Supreme Court of Justice (STJ) and other procedural documents of the case that is publicly accessible, in line with the analysis of official documents that guide the policy of the Federative Republic of Brazil within the scope of the Prison System. Against the above, it was observed that the protection offered by the State has been insufficient in the face of the complex process of violation of Human Rights, in addition to a potential collapse in the public security system.

Keywords: LGBTI+. Habeas Corpus. Prision System. Deprivation of liberty. Human Rights

\section{Introdução}

A presente pesquisa objetiva analisar à luz do princípio constitucional da Dignidade da Pessoa Humana qual relação os corpos de pessoas Transexuais, Travestis e Transgêneros estabelece com o Sistema de Justiça brasileiro, em específico com o Sistema Prisional Brasileiro, examinar se a proteção oferecida pelo Estado brasileiro tem sido suficiente para garantir às pessoas Travestis, Transexuais e Transgênero acesso aos direitos fundamentais durante o período em que cumprem pena nos estabelecimentos prisionais e, por fim, verificar como a falta de políticas pública que ampare esta população no sentido de coibir violações de direito configura e potencializa uma grave ameaça aos Direitos Humanos em pleno século XXI.

No primeiro momento fomentouse por meio de uma breve discussão os conceitos de gêneros, perpassando pelas compreensões acerca das identidades de gêneros, observando como as tratativas internacionais têm procurado interpretar as identidades de gêneros e orientação sexual à luz dos Direitos Humanos, visando combater ações de discriminação, estigma e violência vivenciado cotidianamente pela população LGBTI+, discutiu-se como a já superada visão biologicista de gêneros ainda se mostra como um dos principais entraves na produção de políticas 
públicas centrada sob a égide humanista e progressista, seguido de uma contextualização dos dados sobre a população carcerária no Brasil, e por fim, analisou-se o caso D.S.S à luz do princípio da dignidade da pessoa humana.

Diante do presente quadro utilizamos como metodologia de pesquisa estudos bibliográficos, recorrendo ao método hipotético dedutivo, apoiando-se no estudo do caso D.S.S do Rio Grande do Sul (RS) por meio do Habeas Corpus (HC) no 497.226 - Rs (2019/0065773-1) proferido pelo Ministro Rogerio Schietti Cruz do Supremo Tribunal de Justiça (STJ) e demais peças processuais do caso que estejam em caráter de domínio público, alinhado à análise de documentos oficiais que norteiam a política da República Federativa do Brasil no âmbito do Sistema Prisional.

\section{CONCEITOS IDENTIDADES} DE

Adentrando na análise das categorias Identidades, Identidades Gêneros e Orientaçã Sexual ou Identidades Sexoafetivas, importante se faz, antes de percorrermos tal caminho, explicitarmos o que aqui se entende por identidades. Nesse sentido, HALL (2006), afirma que as velhas identidades, que por tanto tempo estabilizaram o mundo social, estão em declínio, fazendo surgir novas identidades fragmentando o indivíduo moderno, culminando no processo denominado de "Crise de Identidade".

Nas palavras do autor "[...] Tal crise é observada como parte de um processo mais amplos de mudança, que está deslocando as estruturas e processos centrais das sociedades modernas e abalando os quadros de referência que davam aos indivíduos uma ancoragem estável no mundo social" (HALL, 2006: 07)

Assim sendo, a identidade é o liame que o sujeito social - eu estabelece com a sociedade - outros produzindo neste - o sujeito - uma série de interligações culturais que de algum modo traduz no sujeito leituras acerca dos locais/posições que este ocupa no mundo social e cultural em um dado período.

Às vezes, mesmo de forma desapercebida, de alguma maneira, somos, enquanto sujeitos, interpelados no nosso cotidiano por questionamentos que refletem nas nossas identidade, como por exemplo: Quem é você? Local 
de nascimento? Qual a Identificação Racial do sujeito? Qual seu gênero? e etc. Tais indagações, apesar transparecer simplório, constrói no imaginário social ideias previamente codificada acerca das identidades que compõem cada ator social, além de evidenciar os modos como nos identificamos em relação aos múltiplos aspectos sócio-culturais e como somos compreendidos perante as demais pessoas.

\section{IDENTIDADES}

DE

\section{GÊNEROS}

Os estudos sobre Identidades

Sexuais e Identidades de Gêneros surgem imbuídos com as pautas levantadas pelos movimentos feministas e, posteriormente foi agregado pelo movimento de Lésbicas, Gays, Bissexuais, Travestis e Transexuais e Interssxuais (LGBTI+). Destaca-se acerca dos movimentos feministas que este não se molda de forma uniforme, pois é, de certa maneira antagônica, sendo dividido por grande parte dos(as) estudiosos(as) em três "ondas", contudo tal divisão é passível de crítica por parte do movimento, uma vez que esta transmite uma ideia de algo momentâneo, de curta duração. Importante se faz, compreender que tal divisão possui um caráter meramente didático, para fins de entendimento dos processos mais relevantes, pois o movimento não para de acontecer, apenas apresenta fatos que se destacam mais, o processo histórico, em si, é algo recorrente que não é estanque.

Já a história do movimento LGBT é ainda mais recente se comparado ao movimento feminista, sendo pacífico a compreensão que o mesmo se organiza após a conhecida Revolta de Stonewall, ocorrida nos Estados Unidos da América (EUA) em 1969.

Destarte, que foi a partir da segunda onda do movimento feminista que as teorias e conceitos acerca dos gêneros começaram a ser construídos no bojo das reivindicações sociais como um instrumento de análise capaz de denunciar as diferenças e hierarquias existente entre homens e mulheres. PRECIADO (2008), pontua que tal conceito não foi constituído pelo movimento feminista, mas sim por John Money no final dos anos 40 .

Lojes de ser la creación de la agenda feminista de los anõs sesenta, la categoría de género pertenece al discurso biotecnológico de finales d los anõs cuarenta (...) A la rigidez del sexo del siglo XIX, John Money, el psicólogo infantil encargado del 
tratamiento de los bebés intersexuales, va a oponer la plasticidad tecnológica del género. Utiliza por primera vez la noción de gender en 1974 y la desarrola clínicamente más tarde con Anke ehrhardt y Joan y John hampson para hablar de la posibilidad de modificar hormonal y quirúrgicamente el sexo de los bebés nacidos con órganos gentales y/o cromosomas que la medicina, con sus criterios visuales y discursivos, no puede clasificar solo como femeninos o masculinos. (PRECIADO 2008: 81)

Todavia, é no cerne dos movimentos feministas que o conceito de gêneros ganha maior espaço nas pautas políticas, cabe ainda destacar que tal conceito enquanto mecanismo analítico flexível e multifatorial, surge imbuído na produção científica e tecnológica sobre o corpo, de tal modo a nos permitir identificar e compreender as identidades de gêneros como uma ferramenta de inspeção crítica capaz de traduzir as fronteiras hierárquicas entre os(as) sujeitos (homens e mulheres), como também se mostra como um potencial aparato apto a provocar um complexo processo de desnaturalização das identidades dos(as) sujeitos.

Sobre tal aspecto JESUS (2012: 05), pontua que “[...] Como as influências sociais não são totalmente visíveis, parece para nós que as diferenças entre homens e mulheres são naturais, totalmente biológicas, quando, na verdade, parte delas é influenciada pelo convívio social".

Nesse ensaio, cabe esclarecer que conforme o Art. $1^{\circ}$, II, do Decreto Federal $\mathrm{n}^{\mathrm{o}}$ 8.727/2016, se entende identidade de gênero como sendo:

[...] a dimensão da identidade de uma pessoa que diz respeito à forma como se relaciona com as representações de masculinidade e feminilidade e como isso se traduz em sua prática social, sem guardar relação necessária com o sexo atribuído no nascimento.

Apesar do caráter progressista da norma e, a mesma estando alinhada com diretrizes internacionais, não é incomum verificar no cotidianamente a falta de entendimento entre identidade de gênero e orientação sexual, ocasionando diferentes situações de constrangimento, violências e desqualificação às pessoas Travestis, Transexuais e Transgêneros, como referir-se a essa população como sendo homens que se vestem de mulher.

Em um dos processos que envolve D.S.S, é possível observar que durante o depoimento da vítima D.M.C ouvida em Juízo - no processo $\mathrm{n}^{\circ}$ 020/2.10.0002128-1 （CNJ:.002128229.2010.8.21.0020) - na Comarca de Palmeira das Missões, $2^{\text {a }}$ Vara Judicial, a 
mesma aduziu que "[...] é proprietária do estabelecimento comercial e, no dia dos fatos, o réu entrou no local vestido de mulher querendo comprar uma corrente de ouro para sua mãe. O réu usava cabelos longos e logo percebeu que se tratava de um homossexual".

No mesmo processo, relata também o Policial Militar, A.M.V que "foi comunicado pela Sala de Operações da Brigada Militar acerca de uma ocorrência de furto em uma relojoaria. Foi repassado aos policiais que $\mathrm{o}$ indivíduo que havia cometido o furto era um homem magro, alto e vestido de mulher".

Observa-se que em vários momentos da vida de D.S.S no sistema de justiça, a negação de sua identidade de gênero é um processo que se materializa de modo incisivo, tempestivo e recorrente. Tal aspecto evidencia a materialização de uma dupla violência a qual acompanha não só D.S.S, mas tantos(as) outras pessoas Transexuais, Travestis e Transexuais no Brasil.

Essa violência simbólica iniciacom negação material e formal de realização de vida em sociedade, como também, na incansável negação de serem - as pessoas Transexuais, Travestis e Transexuais - reconhecidas em suas plenitudes em função das engrenagens do Estado.

Sobre tal aspecto MAGNO (et al., 2018: 09), elucida que "o processo de estigmatização [de pessoas Transexuais, Travestis e Transexuais] opera por intermédio da identificação de rótulos depreciativos".

À título explicativo optou-se pela exposição dos conceitos básicos acerca dos conceitos de identidade de gênero e seus variantes que, adiante, na análise, serão fundamentais, tendo sido extraídos da obra de JESUS (2012: 13-17), cuja referência completa está no final deste artigo.

Gênero: Classificação pessoal e social das pessoas como homens ou mulheres. Orienta papéis e expressões de gênero. Independe do sexo. Identidade de gênero: Gênero com o qual uma pessoa se identifica, que pode ou não concordar com o gênero que lhe foi atribuído quando de seu nascimento. Diferente da sexualidade da pessoa. Identidade de gênero e orientação sexual são dimensões diferentes e que não se confundem. Pessoas transexuais podem ser heterossexuais, lésbicas, gays ou bissexuais, tanto quanto as pessoas cisgênero. Cisgênero: Conceito "guardachuva" que abrange as pessoas que 
se identificam com o gênero que lhes foi determinado quando de seu nascimento. Transexual: Termo genérico que caracteriza a pessoa que não se identifica com o gênero que lhe foi atribuído quando de seu nascimento. Evite utilizar o termo isoladamente, pois soa ofensivo para pessoas transexuais, pelo fato de essa ser uma de suas características, entre outras, e não a única. Sempre se refira à pessoa como mulher transexual ou como homem transexual, de acordo com o gênero com o qual ela se identifica.

Mulher transexual: Pessoa que reivindica o reconhecimento social e legal como mulher. Algumas também se denominam transmulheres ou Male-to-Female (MtF). Homem Transexual: Pessoa que reivindica o reconhecimento social e legal como homem. Alguns também se denominam transhomens ou Female-to-Male (FtM). Travesti: Pessoa que vivencia papéis de gênero feminino, mas não se reconhece como homem ou mulher, entendendo-se como integrante de um terceiro gênero ou de um não-gênero. Referir-se a

3 A Yogyakarta é um documento Internacional elaborado pela Comissão Internacional de Juristas e o Serviço Internacional de Direitos Humanos, com o objetivo de desenvolver um conjunto de princípios jurídicos internacionais sobre a ela sempre no feminino, o artigo "a" é a forma respeitosa de tratamento. Transgênero: Conceito "guarda-chuva" que abrange o grupo diversificado de pessoas que não se identificam, em graus diferentes, com comportamentos e/ou papéis esperados do gênero que lhes foi determinado quando de seu nascimento. Orientação Sexual/Identidade Sexo-Afetivo: Atração afetivo-sexual por alguém. Sexualidade. Diferente do senso pessoal de pertencer a algum gênero.

\section{VISÃO BIOLOGICISTA DE GÊNERO VS POLÍTICAS PÚBLICAS}

Apesar da avançada compreensão estabelecida em 2006 pela Yogyakarta $^{3}$ e por outros documentos de anos anteriores na órbita internacional, há que observar que na esfera nacional brasileira o processo legislativo tem se mostrado tímido, tendendo a conferir dentro das legislações do Brasil uma perigosa visão biologicista aparada na dicotomia de que pessoas transexuais são

aplicação da legislação internacional às violações de direitos humanos com base na orientação sexual e identidade de gênero. Disponível em: <http://www.clam.org.br/uploads/conteudo/ principios_de_yogyakarta.pdf $>$ 
compreendidas diferentemente de pessoas Travestis, por esta primeira prescindir de realização de cirurgia de transgenitalização e a segunda não, revelando um contrassenso ao estabelecido na Yogyakarta, além de um grave violação ao princípio da dignidade da pessoa humana, por negar aos(às) sujeitos(as) o direito de viver suas experiências pessoais.

São visões normativas limitadas como a Ordem de serviço n ${ }^{\circ}$ 345/2017 da Subsecretaria do Sistema Penitenciário do Distrito Federal (DF), cujo artigo $9^{\circ}$ autoriza a transferência para a Penitenciária Feminina do Distrito Federal apenas de mulheres trans que já tenham realizado cirurgia de transgenitalização do sexo masculino para o feminino que legitimam as cotidianas agressões, brutalidades e violências cometida às pessoas Transexuais, Travestis e Transgêneros, como as sofridas pela Travesti Verônica Bolina no ano de 2015 quando foi violentamente agredida por agentes e policiais no pátio da carceragem do $2^{\circ}$ Distrito Policial, no Bom Retiro, Estado de São Paulo (SP).

No ano de 2018 o Habeas Corpus (HC) $\quad \mathrm{n}^{\circ} \quad 00022531720188070015$, julgado pela Vara de Execuções Penais do Distrito Federal, denegou à C.D.B, T.B, B. J.N.S, A.R.N, R.R.C, D.G.A, L.O.S, C.F.G, L.P.C, A.S.V a possibilidade de cumprirmento de pena em local menos hostil, pois $\mathrm{o}$ estabelecimento o qual estavam lotadas, nas palavras de seus representantes legais “[...] não lhes preserva, por inteiro, a dignidade inerente às suas identidades de gênero", possibilitando-a vivenciar potenciais violações físicas, psicológicas e morais.

Assim decidiu o Tribunal:

“[...] Trata-se de Habeas Corpus impetrado por ANDERSON CAVICHIOLI, BRUNO CARVALHO DE ALMEIDA e MICHEL PLATINI GOMES FERNANDES em favor das pacientes [C.D.B, T.B, B. J.N.S, A.R.N, R.R.C, D.G.A, L.O.S, C.F.G, L.P.C, A.S.V] com a finalidade de que, concedida a ordem, sejam as pacientes, transexuais femininas ou travestis, transferidas para estabelecimento prisional compatível com suas identidades de gênero. [...] Desse modo, considerando que os impetrantes levantaram questões exclusivamente de direito, que independem de análise fáticoprobatória, concluo não haver óbice à análise do pedido formulado neste feito originário, $o$ que faço de ofício, nos moldes previstos nos artigos $194 \mathrm{e}$ seguintes da LEP. [...] Um primeiro ponto a ser esclarecido diz respeito ao alcance da decisão proferida em sede do $\mathrm{HC} \mathrm{n}^{\circ}$ $152.491 / \mathrm{SP}$, a qual, diga-se, não alcançou efeito erga omnes. O Excelentíssimo Senhor Ministro Barroso determinou realmente a transferência de duas travestis que 
estavam alocadas em cela masculina "para estabelecimento prisional compatível com a orientação sexual" (sem menção expressa a presidio feminino), porque ambas estariam presas na penitenciária de Presidente Prudente em uma cela onde havia cerca de trinta homens. [...] Notese que a própria Resolução Conjunta 1 do Conselho Nacional de Combate à Discriminação estabelece que a pessoa travesti ou transexual em privação de liberdade deve contar com espaços de vivência específicos, sem referência expressa a presídio feminino. [...] Destarte, todos nós somos socialmente iguais, mas biologicamente existem diferenças que são cientificamente inegáveis. A musculatura esquelética de quem nasceu homem tem fator hormonal que lhe assegura vantagem de força sobre a mulher. Além do mais, mulher trans, por exemplo, não menstrua como a mulher cis, sendo cediço que durante o período menstrual a mulher cis passa por período de mudança de humor, dores, prostrações, etc. Faz-se necessário trazer a baila tais diferenças, para rebater a pretensão dos impetrantes, os quais pretendem que as pacientes - todas mulheres trans que não fizeram cirurgia de transgenitalização e, por isso, todas têm pênis - sejam transferidas para o presídio feminino e sejam alocadas junto com mulheres cis. Para preservação do direito de uns, não pode haver desrespeito aos direitos de outros, sejam eles quais forem. Por todo o exposto, julgo improcedentes os pedidos formulados e INDEFIRO a transferência. Intime-se o Ministério Público e a Defesa. Remetam cópia da presente decisão à SESIPE. Nada mais havendo, arquive-se".
Nesse sentido que apesar dos grandes avanços científico no campo das ciências humanas e sociais, como também em demais áreas do conhecimento, ainda é possível notar na seara Institucional, assim como no cotidiano social a predominância irrestrita em compreender as identidades de gêneros como sendo algo intrínseco e determinado unicamente pelos órgãos genitais, o que para os(as) estudiosos(as) como Judith Butler, Jaqueline Gomes de Jesus, Berenice Bento, Maria Clara Araújo e tantos(as) outros(as) se mostra, além de uma violência extremada, uma incompatibilidade para com múltiplas formas de ser/estar no universo social.

\section{A DESUMANIZAÇÃO DOS CORPOS}

$\mathrm{O}$ processo de desumanização dos corpos de pessoas Transexuais e Travestis na ótica de Maria Clara Araújo no ensaio Afrotransfeminismo $e \quad a$ necessidade de quilombos de afeto para travestis negras brasileiras (2018), nos direciona para o entendimento de que este processo emerge a partir de uma complexa ordem "[...] que ceifa quaisquer possibilidades reais de existência com dignidade para as travestis que vivem no Brasil". 


\section{Nos afirma OLIVEIRA e} PORTO (2016: 333) que “[...] as possibilidades de ascensão social e a manutenção de uma vida digna são drasticamente suprimidas, levando a grande maioria dessa população [ Travestis, Transexuais e Transgênero] à prostituição e situação de rua"

- Acerca de tal aspecto, FERREIRA (2018) infere que as pessoas LGBTs, sempre experimentaram a privação da liberdade tanto quanto $\mathrm{o}$ restante da população - ou ao menos desde que as prisões “estão aí". Nesse conjunto de sentidos endossamos a compreensão que a privação de liberdade acentua, sem sombras de dúvidas, uma profunda precarização da vida dos(as) sujeitos(as), sendo este - a precarização resultado de uma complexa engrenagem política que nas palavras de FERREIRA (2016: 27) “[...] além de não ressocializar, estigmatiza, viola direitos humanos, rompe com laços sociais, segrega". Ou seja, ultrapassa os limites geopolíticos dos estabelecimentos penitenciários e coloca sobre os corpos codificados por esse sistema uma série de demarcadores.

Aqui ampliamos o entendimento de privação para além do ambiente prisional, compreendendo que tal fato acompanha pessoas Travestis, Transexuais e Transgêneros em grande parte de suas vidas, se não na sua totalidade, negando-lhes direitos fundamentais até efetivas possibilidades de vida.

É nesse cenário que Bento (2011: 01) depreende que "[...] pessoas transexuais e travestis são expulsas de casa, não conseguem estudar, não conseguem emprego, são excluídas de todos os campos sociais".

\section{O DILEMA DO SISTEMA PRISIONAL BRASILEIRO}

$\mathrm{O}$ aumento do número de pessoas privadas de liberdade no Brasil nas últimas décadas tem suscitado à academia, bem como, aos movimentos sociais em prol dos direitos humanos, a necessidade de compreensão deste fenômeno que nos atravessa enquanto sujeitos(as). Apreender o modus operandis de um sistema tão complexo, como o Sistema Prisional brasileiro, demanda um intenso aprofundamento teórico, pois se por um lado é importante investigar $\mathrm{o}$ fenômeno do encarceramento de tal forma a nos permitir apurar os motivos que tem elevado o número de pessoas encarceradas, por outro, não menos 
importante, faz-se necessário verificar além das sentenças proferidas pelos tribunais, o perfil sócio-demográfico desta população, as demandas e os impactos que esse quantitativo gera na gestão de políticas públicas, assim como, as implicâncias do aprisionamento na vida $\operatorname{dos}($ as) apenados(as) e seu grupo familiar.

Aponta o Ministério da Justiça e Segurança Pública, por meio do Levantamento Nacional de Informações Penitenciárias Atualização - Junho de 2016, do Departamento Penitenciário Nacional demonstra que no Brasil havia cerca de 726.712 mil pessoas cadastradas no sistema como privadas de liberdade, incluídas as prisões civis e internações como medidas de segurança em 1.422 unidades prisionais que participaram do levantamento, evidencia a existência de um déficit de 358.663 vagas, uma taxa de ocupação 197,4\% e uma taxa de aprisionamento carcerário de 352,6\% por 100 mil habitantes.

A despeito do Sistema Prisional brasileiro o Supremo Tribunal Federal (STF) por meio da Ação de Descumprimento de Preceito Fundamental (ADPF) $n^{\circ} 347$, de relatoria do Exmo. Sr. Min. Marco Aurélio, impetrado pelo Partido Socialismo e
Liberdade (PSOL) no ano de 2015, reconheceu que o Sistema Penitenciário Nacional encontrava-se à época em "estado de coisas inconstitucional" em detrimento do acentuado quadro de violação de direitos fundamentais.

Nesse contexto, no ano de 2014 o Governo Federal conjuntamente com demais pastas do executivo, por meio da Resolução Conjunta de no 01/2014, do Conselho Nacional de Política Criminal e Penitenciária -'CNPCP e do Conselho Nacional de Combate à Discriminação CNCD/LGBT, instituiu políticas que garantiu às pessoas LGBTI, em específico pessoas Travestis, Transexuais e Transgênero a possibilidade de cumprirem suas respectivas penas com o mínimo de dignidade e garantias básicas, estabelecendo em seu bojo que:

[...] Art. $3^{\circ}$ - Às travestis e aos gays privados de liberdade em unidades prisionais masculinas, considerando a sua segurança e especial vulnerabilidade, deverão ser oferecidos espaços de vivência específicos.

$\S 1^{\circ}$ - Os espaços para essa população não devem se destinar à aplicação de medida disciplinar ou de qualquer método coercitivo.

$\S 2^{\circ}$ - A transferência da pessoa presa para o espaço de vivência específico ficará condicionada à sua expressa manifestação de vontade.

Art. $4^{\circ}$ - As pessoas transexuais masculinas e femininas devem ser 
encaminhadas para as unidades prisionais femininas.

Parágrafo único - Às mulheres transexuais deverá ser garantido tratamento isonômico ao das demais mulheres em privação de liberdade.

Porém, desde então, observa-se que nos últimos anos nenhuma grande mudança - do ponto de vista estrutural na situação dos estabelecimentos prisionais brasileiros ocorrera, no sentido de adequá-los às novas diretrizes nacionais. Contudo alguns Estados fundado em suas prerrogativas constitucionais estabeleceram políticas públicas estaduais visando a efetivação da política nacional por meio do estabelecimento de alas/celas/pavilhões para pessoas LGBTI, em específico pessoas Travestis, Transexuais e Transgênero, como é o caso do Rio Grande do Sul no Presídio Central de Porto Alegre, Paraíba no Penitenciária Desembargador Flósculo da Nóbrega de João Pessoa, Pernambuco no Presídio de Igarassu na Região Metropolitana de Recife e etc.

No Brasil a propulsora da difusão das garantias constitucionais às pessoas privadas de liberdade foi a Constituição Federal de 1988, a qual incorporou à realidade normativa do País tendências internacionais no tratamento daqueles que por motivos diversos se encontram privados de liberdade, trazendo ao bojo normativo um importante recorte de gênero.

Art. $5^{\circ}$ Todos são iguais perante a lei, sem distinção de qualquer natureza, garantindo-se aos brasileiros e aos estrangeiros residentes no País a inviolabilidade do direito à vida, à liberdade, à igualdade, à segurança e à propriedade, nos termos seguintes:

[...]

XLIX - é assegurado aos presos o respeito à integridade física $\mathrm{e}$ moral;

L - às presidiárias serão asseguradas condições para que possam permanecer com seus filhos durante $\mathrm{o}$ período de amamentação;

A Procuradoria-Geral da República, por meio de ProcuradoraGeral, Exma. Sra. Raquel Elias Ferreira Dodge, no parecer - n. ${ }^{\circ} 544 / 2018$ SFCONST/PGR, Sistema Único n. $^{\circ}$ 335.915/2018 - da Arguição de Descumprimento de Preceito Fundamental 527/DF (2019: 24), ressalta que:

[...] compelir [às] transexuais femininas e travestis a ocuparem"espaços de vivência específicos" em presídios masculinos também constitui medida de segregação, incompatível com o respeito ao direito à igualdade e à nãodiscriminação, por quanto as submete ao constrangimento de permanecerem confinadas em locais restritos dentro do estabelecimento prisional, 
impingindo-lhes rótulo segregacionista e discriminatório.

Destarte, a Coordenação de Políticas Públicas para Mulheres e Promoção das Diversidades, do Ministério da Justiça e Segurança Pública, mediante nota técnica produzida no ano de 2017 dispôs que:

A população LGBT, em geral, integra a parcela particularmente vulnerável no sistema prisional, haja vista os riscos de discriminação e violências (física, psicológica, moral e sexual), mais especificamente para as pessoas trans, considerando o assujeitamento a que elas são submetidas, bem como a exclusão de atividades como esporte e educação, o que faz com esse grupo [sofra] além de uma dupla restrição de liberdade, uma acentuada restrição de direitos.

Por esse ângulo, fundado no conhecimento acerca dos lamentáveis episódios de violência física, moral e sexual vivenciadas por mulheres transexuais, travestis e transgêneros em presídios masculinos, sustenta-se a ideia de que a manutenção de pessoas transexuais, travestis e transgêneros privadas de liberdade em estabelecimento prisional na qual inexista compatibilidade com sua identidade de gênero configura uma grave violação aos direitos humanos e constitucionais.
Sob tal aspecto pondera SOUZA e FERREIRA (2016: 26) que:

“[...] Sob o pretexto de proteção, ou em outras palavras, "em nome do bem", as travestis e mulheres transexuais ainda são expostas a situações desumanizadoras, como por exemplo o cárcere em alas direcionadas a homens que cometeram crimes sexuais como forma de evitar possíveis abusos de outros presos.

Tal situação evidencia uma latente e contínua ofensa aos preceitos Constitucionais inscritos na Carta Magna do Brasil, tão elementares para consolidação do Estado Democrático de Direito, demonstra um descaso para com os compromissos internacionalmente os quais a República Federativa do Brasil é signatário, além de um austero desrespeito à igualdade, à nãodiscriminação, a saúde, a segurança pessoal e os direitos da personalíssimo das pessoas Transexuais, Travestis e Transgênero.

Ainda sobre tal conjuntura $\mathrm{o}$ Relatório de Gestão 2016/2018 do Departamento de Monitoramento e Fiscalização do Sistema Carcerário e do Sistema de Execução de Medidas Socioeducativas - DMF, ratifica que tais violações decorrem das falhas estruturais e da falência de políticas públicas, reitera ainda que eventuais modificações nesse 
quadro problemática depende da implementação de medidas abrangentes de natureza normativa, administrativa e orçamentária, merecendo pronta intervenção do Poder Judiciário com vistas a garantir a necessária proteção dos direitos fundamentais.

Cabe mencionar que o jaz Exmo. Sr. Ministro Teori Zavascki, em seu voto prolatado no Acórdão do julgamento do Recurso Extraordinário no 580.252/MS, o qual discutia-se a violação à direitos fundamentais a detentos em estabelecimentos carcerários no Estado do Mato Grosso do Sul (MS), afirma ao citar FRAGOSO (2005: 06) que “[...] em nossas prisões as condições de vida são intoleráveis” e, na prática, “[...] os presos não têm direitos".

\section{D.S.S E O SISTEMA DE JUSTIÇA}

D.S.S, brasileira,travesti sentenciada a cumprir 13 (treze) anos, 01 (um) mês e 22 (vinte e dois) dias de reclusão, recolhida no Presídio Estadual de Cruz Alta, iniciou a execução da pena em 23 de fevereiro de 2016, no regime fechado, e atualmente em regime semiaberto, em razão da prática delituosa de crimes patrimoniais.
186

Depreende-se dos autos do processo que diante da decisão do Juízo da Vara de Execuções Criminais da Comarca de Cruz Alta, a qual denegou à D.S.S em cumprimento de pena em regime semiaberto, a concessão da saída temporária em decorrência da prática de falta grave ao tempo do pleito, homologada em juízo alterou a data-base para o dia 20-06-2017, não alcançando assim o cumprimento de 1/4 da sanção a que foi condenada, o que obstaculiza o alcance da almejado beneficie, bem como o pernoite em cela feminina.

Diante de tal feito, a Defensoria Pública do estado do Rio Grande do Sul (RS), representante legal de D.S.S, interpôs junto à Oitava Câmara Criminal do TJ/RS, o Agravo de Execução - $n^{\circ}$ $70080189442 \quad\left(n^{\circ} \quad\right.$ CNJ: 038415608.2018.8.21.7000) -, de relatora da $\mathrm{Sr}^{\mathrm{a}}$

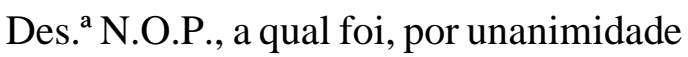
dos(as) Desembargadores(as), novamente negado.

Assim manifestou-se sobre a controvérsia o TJ/RS:

"De igual forma, não comporta acolhida o pedido de pernoite do segregado no alojamento feminino. Isso porque, ainda que o agravante descreva sua condição de gênero, indicando que é travesti, o que lhe faz possuir aparência e características femininas, tanto não é suficiente para autorizar que resgate sua 
sanção em alojamento destinado às mulheres. [...] Não resta dúvida no sentido de que a melhor alternativa seria a instalação de celas especiais visando atender às necessidades dos apenados em seus diferentes níveis, inclusive opção sexual [...] Contudo, essa não é a situação do Presídio Estadual de Cruz Alta. [...] O fato é que se a concessão do pleito traria consequências de ordem e de disciplina no cárcere, como adiantado pela administração do alojamento, tanto atingiria a totalidade dos presos que executam sanção no estabelecimento, o que não se mostra plausível. De outro lado, permitir que os travestis cumpram pena em presídio feminino viola a Constituição Federal, no ponto em que segmenta a população carcerária segundo o sexo do preso. [...] Por tais fundamentos, nego provimento ao agravo em execução."

Dito isso, passa-se à análise do caso.

\section{HABEAS CORPUS No $\mathbf{N}^{\circ} 497.226$ - RS (2019/0065773-1)}

No presente remédio constitucional impetrado pela Defensoria Pública do Estado do Rio Grande do Sul (RS), no Superior Tribunal de Justiça (STJ) em fase recursal, em favor da paciente D.S.S, o relator Exmo. Min. Rogerio Schietti Cruz, após expor relato, fundamentos, o pedido preliminar formulado pelo Órgão impetrante, bem como o posicionamento do Tribunal de Justiça do Estado do Rio
Grande do Sul (TJ/RS), passa a decidir a controvérsia.

Importante destacar que conforme alegado pela Defensoria Pública do RS, e diferentemente do arguido pela Juíza no $\mathrm{HC}$ do $\mathrm{DF} \mathrm{n}^{\circ}$ 00022531720188070015, a ausência de cirurgia de transgenitalização não deve materializar-se como fato impeditivo de acesso à direitos, pois condicionar esta população à realização de um procedimento cirúrgico obsta o reconhecimento dos princípios da dignidade da pessoa humana, da não discriminação, autodeterminação, da busca da felicidade, estes tão valiosos ao Estado democrático de direito, além de evidenciar um total desconhecimento acerca das realidades de vida das pessoas LGBTI+, em específico pessoas travestis, transexuais e transgêneros no que concerne ao acesso às políticas públicas de saúde no Brasil.

Preceitua a Constituição Federal da República do Brasil (CFRB) em seu Art. $3^{\circ}$ os objetivos fundamentais que regentes deste Estado Soberano, dentre estes destaca-se inciso IV.

Art. $3^{\circ}$ Constituem objetivos fundamentais da República Federativa do Brasil:

[...]

IV. promover o bem de todos, sem preconceitos de origem, raça, 
sexo, cor, idade e quaisquer outras formas de discriminação.

Assim, argumentar que garantir às pessoas Transexuais, Travestis e Transgêneros o direito a cumprirem pena em presídio feminino viola a Constituição Federal, fundado na interpretação do Art. 5 XLVIII, aponta para uma interpretação restrita e biologicista de tal dispositivo constitucional, além de uma análise desconexa do bojo principiológico constitutivo da CFRB, bem como das normas internacionais as quais o Brasil é signatário.

Frise-se, que durante a aplicação do direito, o Órgão Julgador deve, imbuído no sistemático exercício hermenêutico, proferir solução in cause ponderando a norma escrita e os valores pluralísticos envolto nas distintas realidades sociais que compõe o território nacional.

Nesse direcionamento, garantiu a resolução Resolução Conjunta $n^{\circ} 01 / 2014$ do Conselho Nacional de Combate a Discriminação em seu Art. $3^{\circ}$ o direito às travestis e aos gays privados de liberdade em unidades prisionais masculinas espaços de vivência específicos. Já às pessoas transexuais masculinas e femininas, o mesmo dispositivo legal garantiu o direito destas(es) serem encaminhadas(aos) para unidades prisionais femininas.

Art. $3^{\circ}$ Às travestis e aos gays
privados de liberdade em unidades
prisionais masculinas,
considerando a sua segurança e
especial vulnerabilidade, deverão
ser oferecidos espaços de vivência
específicos.
Art. $4^{\circ}$ As pessoas transexuais
masculinas e femininas devem ser
encaminhadas para as unidades
prisionais femininas
Parágrafo único. Às mulheres
transexuais deverá ser garantido
tratamento isonômico ao das
demais mulheres em privação de
liberdade.

Já em fase de decisão o Ministro Rogerio Schietti Cruz, com base nas condições do Presídio Estadual de Cruz Alta frente ao direito invocado na exordial, na busca pela solução ideal alvitrada, alinhado aos riscos gerados pelas normas patriarcais e pelo preconceito que atravessa a sociedade e ganha maior vazão dentro das unidades prisionais, agravada pela promiscuidade que caracteriza os ambientes carcerários masculinos, pugna pela concessão de liminar determinando a colocação da paciente D.S.S em espaço próprio, compatível com sua identidade de gênero.

\section{Assim decidiu:}

[...] “'̀̀ vista do exposto, concedo a liminar para determinar a colocação da paciente em espaço próprio, compatível com sua identidade de gênero, separada dos 
homens e mulheres que cumprem pena no Presídio Estadual de Cruz Alta. Não sendo, como tudo indica, possível o imediato atendimento desta determinação, deverá a paciente ser colocada na ala feminina no presídio, preferencialmente em cela individual. Sem embargo, na eventual falta de condições para o atendimento também desta determinação - fiando-me no prudente arbítrio da douta autoridade judiciária competente determino que se apliquem, então, os parâmetros fixados no RE n. 641.320/RS."

Em conformidade com o entendimento já preconizado pela súmula vinculante $\mathrm{n}^{\circ}$ 56 do Supremo Tribunal Federal (STF), que "A falta de estabelecimento penal adequado não autoriza a manutenção do condenado em regime prisional mais gravoso, devendo-se observar, nessa hipótese, os parâmetros fixados no RE 641.320/RS".

\section{CONSIDERAÇÕES FINAIS}

Diante do exposto, observa-se que apesar do avanço na produção legislativa e jurídica no âmbito Internacional, verifica-se que, as pessoas Transexuais, Travestis e Transgêneros ainda vivenciam de forma acentuada violências de diferentes ordens sob suas vidas. Assim, quando não amparadas e alcançadas pelas políticas públicas do
Estado no que tange ao pleno acesso à educação, saúde, mercado de trabalho e etc., por exemplo, estes(as) sujeitos(as) sofrem uma ininterrupta situação de vulnerabilização, em decorrência do processo de negação material de realização da vida em sociedade-

O caso D.S.S se coloca como um importante marco, o qual nos permite verificar que, para garantir o adimplemento da pena cominada pelo Estado - compreendo assim a função da pena -, em um local menos hostil que lhe conservasse a dignidade, D.S.S. careceu percorrer um longo e moroso caminho judicial, de tal modo, a evidenciar uma preocupante situação de Periculum In Mora em face da latente violação de direitos individuais e fundamentais.

Destarte, as decisões prolatadas pelos Órgãos Judicias que antecederam ao proferimento do presente $\mathrm{HC}$, demonstram que apesar da República Federativa do Brasil, ser signatário de diferentes marcos legais internacionais, ainda possui uma acentuada carência hermenêutica no que tange a aplicação do direito quando envolve populações marginalizadas e vulnerabilizadas, como os(as) LGBTI+, em decorrência de uma limitada compreensão acerca dos 
estudos de gêneros e suas nuances na vida social.

Apesar de solucionável, tal fato, remonta à necessidade de rediscutir na esfera acadêmica a reconstrução de novas bases epistêmicas para a formação de Bacharel(a) em Direito no Brasil, a fim de sanar importantes lacunas na esfera educacional.

Um outro aspecto derivado de todo o bojo elencado ao longo dos parágrafos supra, reside na preocupante escassez de políticas públicas específicas para pessoas LGBTI, principalmente Travestis, Transexuais e Transgênero privadas de liberdade.

Um outro dado proveniente desta pesquisa localiza-se na falta de capacidade de gerenciamento do Sistema Prisional por parte do Estado brasileiro, episódio o qual representa na vida dos(as) apenados(as) e segmentos populacionais vulnerabilizados, uma iminente degradação humana, resultado das políticas de encarceramento em massa, articulado à política de seletividade da população carcerária e por fim, na falta de investimento público no setor de Segurança Pública.

Dessa forma, MONTEIRO e CARDOSO (2013) observa uma intrínseca ligação entre o inchaço sem precedentes do sistema penitenciário brasileiro e o incentivo às políticas repressivas respaldadas por uma lógica de encarceramento.

Sob tal aspecto revela, RODRIGUES (2019), em seu texto "Quem perseguiu as travestis durante a ditadura militar?" que:

As violências contra as travestis
foram tidas como um projeto de
Estado que visava possibilitar uma
higienização social como meio de
garantir um controle e ordem sobre
o que era apresentado enquanto
"abjeto" e "marginalizado" por
parte da sociedade brasileira e
diversas instituições de poder.
Travestis foram introduzidas a
processos de violências e
perseguição por parte,
principalmente, da polícia e da
imprensa.

Por fim, cabe destacar que a superlotação e o déficit no sistema carcerário, assim como, as violações dos direitos humanos não são fatos do mero acaso. Sobre tais situações, MONTEIRO e CARDOSO (2013: 111), infere que "tais arbitrariedades podem nos fornecer elementos para compreender o sistema prisional brasileiro nos termos de um campo, no qual direito e fato tornam-se indiscerníveis", pois de alguma maneira, tais fatos representam o modo como o Estado tem sido negligente, bem como, conivente com as contínuas violações 
que lastreiam a vida das pessoas privadas de liberdade no Brasil.

\section{Referências Bibliográficas:}

Araújo, Maria Clara. (2018), "Afrotransfeminismo e a necessidade de quilombos de afeto para travestis negras brasileiras". Disponível em: $<$ https://www.almapreta.com/editorias/o -quilombo/afrotransfeminismo-e-a$\underline{\text { necessidade-de-quilombos-de-afeto- }}$ para-travestis-negras-brasileiras > $\quad 25$ jul. 2018. Acessado em: 15 abr 2019.

Bento, Berenice. Na escola se aprende que a diferença faz a diferença. Rev. Estud. Fem., Florianópolis , v. 19,nº.2. 2011.

Brasil. Supremo Tribunal Federal. Arguição de Descumprimento de Preceito Fundamental No 347/DF. Rel. Min.. Marco Aurélio. Brasília, DF, 2010. Conselho Nacional de Justiça

(CNJ). Relatório de Gestão 2016/2018 Departamento de Monitoramento e Fiscalização do Sistema Carcerário e do Sistema de Execução de Medidas Socioeducativas $\quad$ (DMF), 2018. Disponível
191

em: $<$ http://www.cnj.jus.br/files/conteud o/arquivo/2018/09/76a8fead0d7abe6ae2 ccb8282a113b64.pdf>. Acesso em: 11 abr, 2019.

Supremo Tribunal Federal.

Recurso Extraordinário $\mathbf{n}^{\circ}$

580.252/MS. Requerente: Anderson Nunes da Silva. Requerido: Estado de Mato Grosso do Sul. Relator: Ministro Teori Zavascki. Publicado Acórdão, DJE em 11 de setembro de 2017. Disponível em:

$<$ http://portal.stf.jus.br/processos/downl oadPeca. $\cdot$ asp? $\mathrm{id}=312692053 \& \mathrm{ext}=. \mathrm{pdf}>$. Acesso em: 02 de abr de 2019. Supremo Tribunal Federal. Súmula Vinculante 56. A falta de estabelecimento penal adequado não autoriza a manutenção do condenado em regime prisional mais gravoso, devendose observar, nessa hipótese, os parâmetros fixados no RE 641.320/RS.

DJe $\mathrm{n}^{\mathrm{o}} 165$ de 08/08/2016, p. 1. Disponível em:<http://www.stf.jus.br/portal/jurispr udencia/listarJurisprudencia.asp?s1=56. $\underline{\text { NUME.\%20E\%20S.FLSV.\&base=base }}$

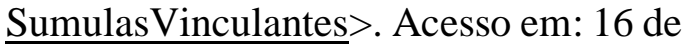
abr de 2019. 
Superior Tribunal de Justiça

(STJ). Habeas Corpus $n^{\circ}$ HABEAS

CORPUS $\quad \mathrm{N}^{\circ} \quad 497.226 \quad-\quad \mathrm{RS}$

(2019/0065773-1). Rel. Ministro

Rogerio Schietti Cruz. Brasília, Distrito

Federal (DF). 2019

Tribunal de Justiça do Distrito

Federal e dos Territórios. Vara de

Execuções Penais do DF. Habeas

Corpus $n^{0} \quad 00022531720188070015$.

Rel. Juíza de Direito Leila Cury, Brasília (DF), 2018.

. Tribunal de Justiça do Estado do

Rio Grande do Sul (TJ/RS), Oitava

Câmara Criminal. Agravo de Execução $n^{0} 70080189442$ (n $n^{0}$ CNJ: 038415608.2018.8.21.7000). Rel. DES. ${ }^{a}$ Naele Ochoa Piazzeta, Rio Grande do Sul (RS). 2019

. Ministério da Justiça.

Resolução Conjunta n01/2014

CNPCP-CNCD/LGBT, de 15 de abril de 2014. Brasilia, 2014, DF. Disponível em:

$<$ http://pesquisa.in.gov.br/imprensa/jsp/ visualiza/index.jsp?jornal $=1 \&$ pagina $=1$ $\underline{\text { data }=17 / 04 / 2014>}$. Acesso em: 18 abr. 2019
192

Levantamento Nacional de Informações Penitenciárias INFOPEN Atualizado - Junho de 2016

I organização, Thandara Santos; colaboração, Marlene Inês de Rosa [et al]. Brasília: Ministério da Justiça Segurança Pública. Departamento Penitenciário Nacional, 2017. Acesso em: 08 abr. 2019.

_. Nota Técnica $\mathrm{n}^{\mathrm{o}}$ 2/2017/COPMD/DIRPP/DEPEN,

Íntegra. Disponível em:<https://www.anadep.org.br/wtksite/ grm/envio/2281/SEI_08016.008235_20 17_39.pdf>. Acesso em 22 abr. 2019.

Procuradoria-Geral da República, Documento- n. ${ }^{\circ} 544$ /2018SFCONST/PGR, Sistema Único n. ${ }^{\circ}$ 335.915/2018. Arguição de Descumprimento de Preceito Fundamental 527/DF. Disponível em: $<$ http://www.mpf.mp.br/pgr/docume ntos/copy2_of_ADPF_527_transgenero _sistemapenitencrio.pdf $>$. Acesso em 22 abr. 2019.

Decreto $N^{\circ} 8.727$, de 28 de abril de 2016. Dispõe sobre o uso do nome social e o reconhecimento da identidade de gênero de pessoas 
travestis e transexuais no âmbito da administração pública federal direta, autárquica e fundacional. Disponível em< $<$ http://www.planalto.gov.br/ccivil_0 3/_Ato2015-

2018/2016/Decreto/D8727.htm>.

Acesso em: 23 de abril de 2019.

Ferreira, Guilherme Gomes. "É TIPO UM LABIRINTO”: LGBTs EM PRIVAÇÃO DE LIBERDADE. Anais eletrônicos do VII Seminário Corpo, Gênero e Sexualidade, do III Seminário Internacional Corpo, Gênero e Sexualidade e do III Luso-Brasileiro Educação em Sexualidade, Gênero, Saúde e Sustentabilidade [recurso eletrônico] / organizadoras, Paula Regina Costa Ribeiro... [et al.] - Rio Grande : Ed. da FURG, 2018. Disponível em:

https://7seminario.furg.br/images/arquiv o/241.pdf. Acesso em 10 abr. 2019.

Hall, Stuart. A identidade cultural na pós-modernidade; tradução Tomaz Tadeu da Silva, Guaraeira Lopes Louro - 11. ed - Rio de Janeiro: DP\&A, 2006.

Jesus, Jaqueline Gomes de. Orientações sobre a população transgênero: conceitos e termos / Jaqueline Gomes de
Jesus. Brasília: Autor, 2012. Disponível em:

https://www.sertao.ufg.br/up/16/o/ORIE NTA\%C3\%87\%C3\%95ES_POPULA\% C3\%87\%C3\%830_TRANS.pdf?13340

65989. Acesso em: 07 abr. 2019

Magno, Laio et al. Estigma e resistência entre travestis e mulheres transexuais em Salvador, Bahia, Brasil. Cadernos de Saúde Pública, v. 34, p. e00135917, 2018.

Monteiro, Felipe Mattos; Cardoso, Gabriela Ribeiro. A seletividade do sistema prisional brasileiro e o perfil da população carcerária: um debate oportuno. Civitas-Revista de Ciências Sociais, v. 13, n. 1, p. 93-117, 2013.

Oliveira, João Felipe Zini Cavalcante; Porto, Tauane Caldeira. A transfobia e a negação de direitos sociais: A luta de travestis e transexuais pelo acesso à educação. In: Anais do Congresso Latino-Americano de Gênero e Religião. 2016. p. 332-336.

Preciado, Paul B. Testo yonqui. Madrid: Espasa, 2008. 
Rodrigues, Ana Flor Fernandes

(2019),“Quem perseguiu as travestis

durante a ditadura militar?"

Disponível

em:<https://medium.com/@anaflorferna

ndesrodrigues/quem-perseguiu-as-

$\underline{\text { travestis-durante-a-ditadura-militar- }}$

ba694fe8ece0>. Acessado em: 15 abr 2019.

Souza, Bruna Caldieraro de; Ferreira, Guilherme Gomes. Execução Penal e População de Travestis e Mulheres Transexuais: o caso do presídio central de Porto Alegre. Cadernos de Gênero e Diversidade, v. 2, n. 1, 2016 